\title{
CHANGES IN THE CORIUM AND SUBCUTANEOUS TISSUES AS A CAUSE OF RHEUMATIC PAIN
}

\author{
BY \\ DORIS M. BAKER \\ London
}

(RECEIVED FOR PUBLICATION 9 MAY, 1955)

In a previous communication (Baker, 1951), an account was given of a clinical syndrome called panniculitis, and it was suggested that the morbid anatomy was different from that hitherto described. The condition is common at the menopause, whether natural or artificial, probably for two reasons:

(1) there is often a rapid increase in weight;

(2) there is a readjustment in endocrine function.

The syndrome can also occur in quite young people, though this is less usual.

The patient's added bulk may be evenly distributed, but commonly certain areas of the body are more affected than others. The areas usually involved are the region of the deltoid muscles, the back of the upper arm, the back of the neck, the pectoral muscles, the lumbar region, sacrum, and buttocks, the front of the lower leg, and at times the region of the heel to either side of the Achilles tendon (Fig. 1). For diagnosis a convenient spot to examine is in front of the external auditory meatus in the region of the parotid gland; of my series of cases, 70 per cent. showed the characteristic thickening at this site.

Symptoms.-The patient complains of a feeling of weight or heaviness in the affected parts, giving rise to undue fatigue on exertion. When the added bulk is in the lower limbs and the gluteal region, she is exhausted by walking; when the arms and neck are involved, lifting the arms-as in polishing, typing, or even brushing the hair-can cause fatigue, heaviness, and aching discomfort. In addition, the patient complains of a sore, bruised, or burning feeling when the affected parts are warmed -for example, before a fire or in bed at night. In bed this symptom is one cause of "fidgety legs", for the patient restlessly seeks out cool areas in the bed. The pain is usually felt in patches or areas of the body; and after being for a time in one spot-for example, the front of one thigh-it may spread to a similar position in the other limb, or to another area of the body. In addition to pain, there may be patches of numbness and a sensation of pins and needles, and when such paraesthesiae are bilateral they may cause difficulty in diagnosis. These patients bruise easily, and this may first lead them to seek advice.

Signs.-With this syndrome two main signs are found. First, the skin is tacked down over the affected part so that it is impossible to lift it away from the underlying tissue, and mottling or a peau d'orange effect is produced when the skin texture is tested by palpation. Secondly, over the affected area the skin feels dense, almost indurated, with a lack of elasticity; one of the easiest areas in which to elicit this sign is in front of the external auditory meatus. Many of the indurated areas may be tender on palpation, the tissues feeling bruised or sore. Where the patient complains of numbness, sensation is diminished. Finally, with involvement of the tissues of the face, other than the part, in front of the ear, the appearance is altered by the ironing out of the small lines and wrinkles which give character to the face, and the features may become coarsened.

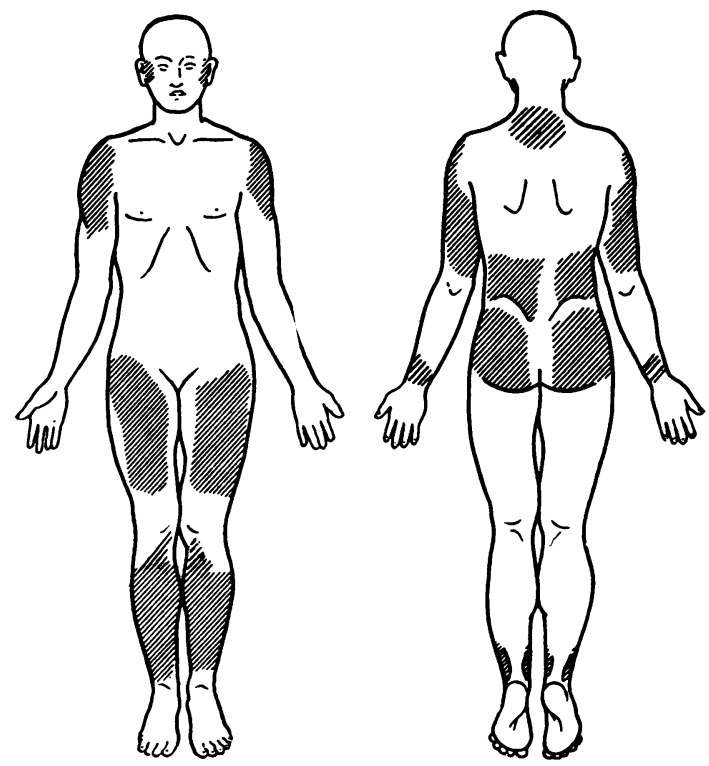

Fig. 1.-Areas most commonly affected by this syndrome. 
The following is a typical case history:

Case 1.-An unmarried woman, aged 51, complained that for 7 weeks she had had burning pain in the front of the left thigh, accompanied by a feeling of numbness and pins and needles. After 2 weeks the pain spread to the front of the right thigh. The limbs felt heavy, and the symptoms were aggravated when she got warm in bed, making her restless and disturbing her sleep; she noticed that she bruised easily. Her weight had increased by over 1 stone in the past 2 years.

No evidence of organic disease was found; but the skin of the thighs showed changes typical of panniculitis and

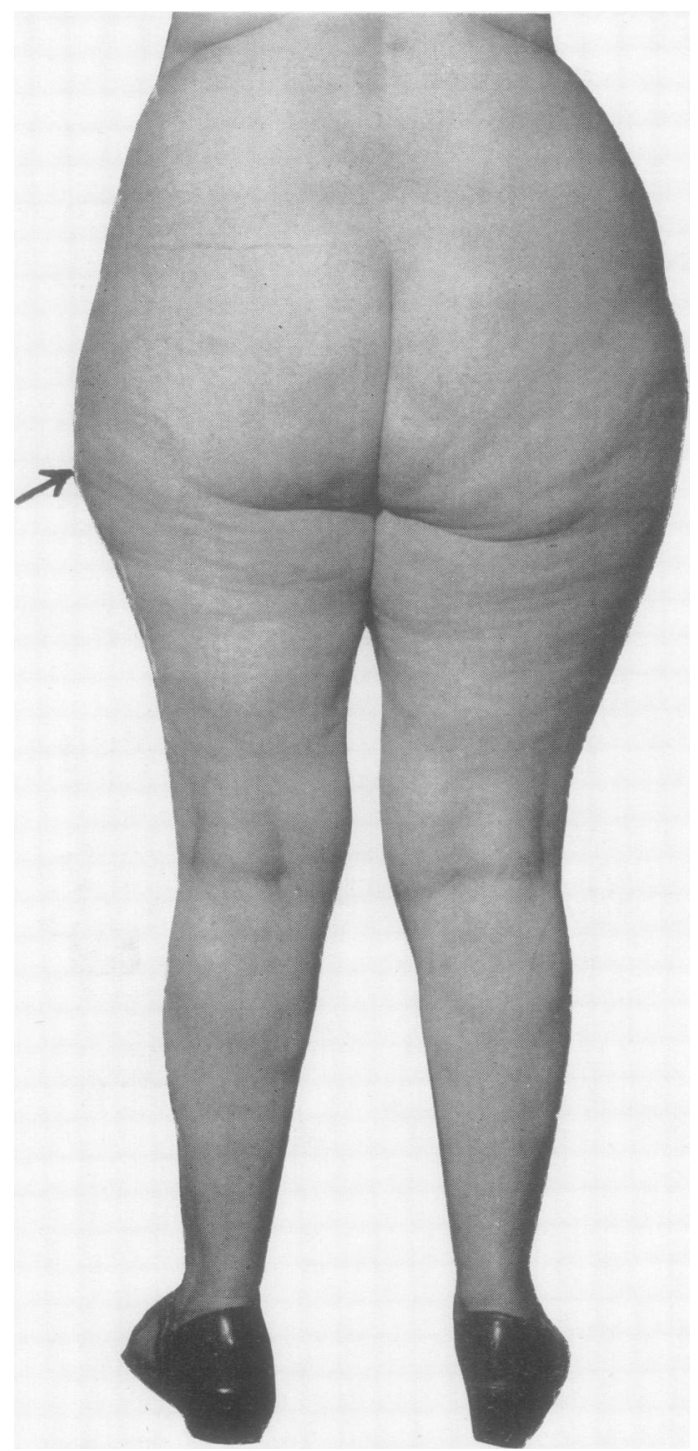

FIG. 2(a).-Case 2, showing enlarged area of thighs. the area of skin in front of the external auditory meatus was tightly tacked down and thickened. Radiographically the hip and knee joints proved normal. Biopsies of skin from the thigh and the arm were compared; that from the thigh showed greater thickness and density of collagen in the dermis than sections from the arm and from a normal thigh.

Progress.-After 3 weeks on a strict low-sodium diet, the patient reported that at first she had been relieved $\bar{S}$ but that latterly the symptoms had returned.

When she was seen 4 months later, the pain and discomfort in the thighs had not improved, except at $\tilde{c}$ night when she was less restless. In the lower part of $\overrightarrow{0}$ both buttocks there was now a bruised and burning feeling, which seemed to radiate into the groins; it felt $\vec{\omega}$ "as if the skin was too tight for the flesh". The skin over the lower part of the buttocks was thickened, tacked down, and very tender; and over the region of the

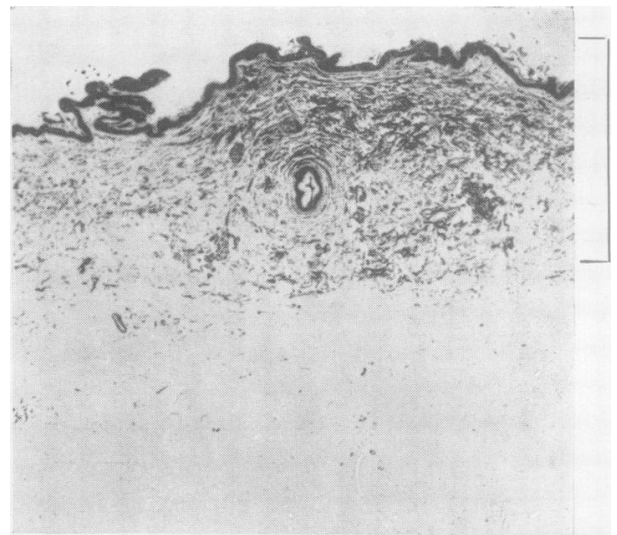

Fig. 2 (b).-Case 2, normal skin from inner side of thigh.

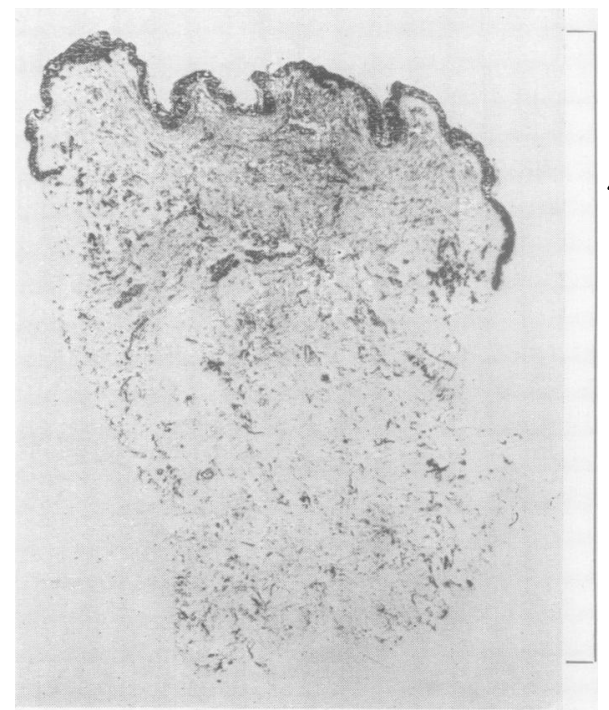

Fig. 2(c).-Case 2, skin from painful area. 
7 th cervical vertebra there was a patch of indurated skin which on palpation gave a sensation of pins and needles.

In general the presentation is as described above, but other manifestations occur of which the following two cases are examples:

Case 2.-A married woman, aged 59, who had had the menopause at the age of 58, came complaining that she was developing "painful tumours" over both hips. The swelling had appeared over the right hip first and had then developed on the left side; she could not lie on her side at night. She had put on a stone in weight over the past 2 years. The patient was organically sound, but over the lateral aspect of each hip there were large pads of indurated tender skin and subcutaneous tissue 8 in. in

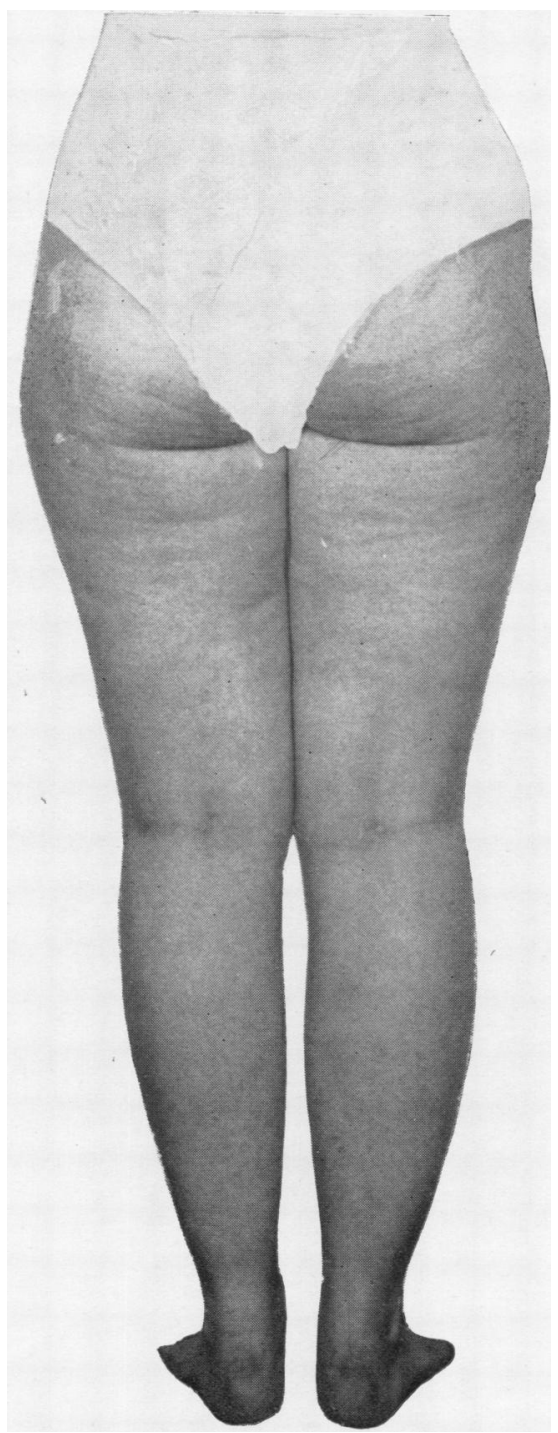

FIG. 3(a).-Case 3, showing normal contour of limbs. diameter (Fig. 2a-c).

Case 3.-An unmarried woman, aged 33, was sent to my general medical out-patients' clinic as she was complaining of swollen legs. Her doctor wrote:

I cannot detect any organic disease of the heart or kidneys to account for this patient's condition, but there is marked swelling of both thighs which feel wooden on palpation and are tender to the touch, the skin seems tied down. Her stockings which normally are loose are now cutting into her thighs.

The patient, on questioning, said she had been putting on weight rapidly during the past year. Her thighs were painful to the touch, the pain was a sore, burning one and it became worse at night in bed. Clinical examination revealed no evidence of organic disease, but the skin of the thighs was tacked down to the underlying tissues, dense, and tough and tender on palpation (Fig. 3a-c).

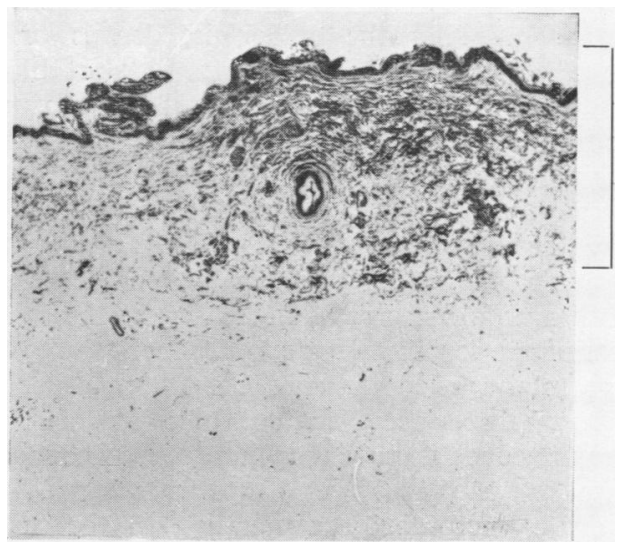

FIG. 3(b).-Normal skin for comparison.

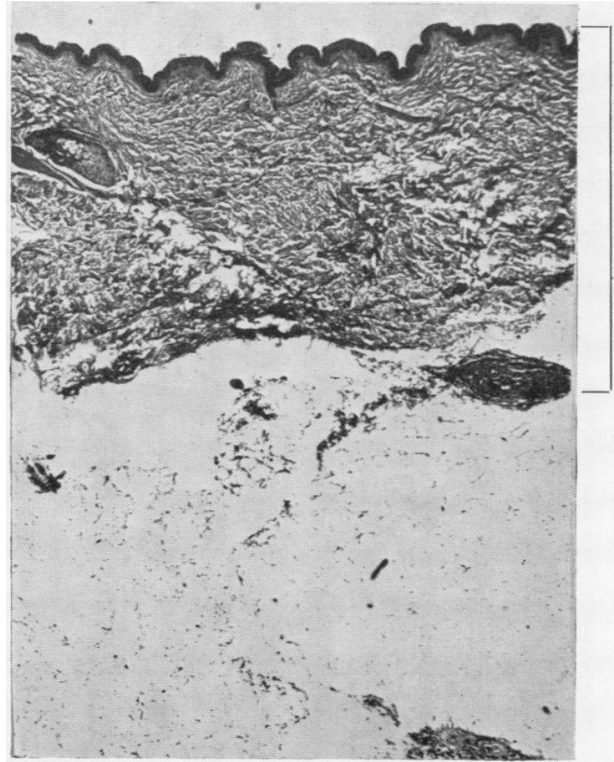

FIG. 3(c).-Skin from affected area. 


\section{Morbid ANATOMY}

Stockman (1911) and Telling (1936) described this condition as an inflammation of the panniculus adiposus with an invariable tendency to proliferative thickening, secondarily involving the nerve fibres in the form of a neuritis. Kling (1937) and Copeman (1949) reported that they found no evidence of inflammatory change. Haram (1951), after examining five skin biopsies, three from pathological areas of skin and two from normal skin, reported that the dermis appeared to be thicker in the three pathological sections than in the two normal sections, with denser collagen bundles in the reticular layer of the former. The subcutaneous fat showed no pathological change, and there was no round celled infiltration or other evidence of inflammatory change in either the epidermis, dermis or subcutaneous tissues. Since 1951, 49 skin biopsies have been taken from patients suffering from this syndrome and seven biopsies from normal skin for controls; five of the latter have been taken from apparently normal areas of skin in patients suffering from this syndrome in other parts of the body. Haram found in 80 per cent. an apparent increase in depth and in some cases in density of the collagen layer of the dermis and in some sections the collagen appears to dip down into the fatty tissue. The collagen fibres were mature and acellular. The subcutaneous fat showed no pathological change and there was no evidence of inflammatory change. Electron microscopic examination of the collagen tissue shows that the period of the striations of the collagen fibrils and the diameter of the individual fibrils is no different from those of normal skin.

Thus these changes confirm the statement that there is no evidence of inflammatory change in this condition, but they also suggest that there is an increase in the depth of the collagen layer in a high percentage of the skin biopsies examined, varying from slight to considerable. The best evidence so far comes from cases where an area of skin from the painful part of a limb is compared with a biopsy from apparently normal skin in the same limb. In the future this would appear to be the only valid comparison to make, although comparison with the skin of the opposite limb might seem suitable. (Figs 4 and 5.)

\section{Correlation between Signs, Symptoms, AND MoRbid ANATOMY}

Before attempting a correlation between the pathological findings and the signs and symptoms, a short description is necessary of certain relevant features of normal skin. According to Lever (1949), collagen forms 98 per cent. of the connective tissue of the corium or dermis; the bundles are only slightly extensible but are wavy and so permit of $\frac{}{3}$ stretching of the skin. The collagen bundles are $\square$ interwoven with a web of elastic fibres which in the papillae run upward and split into fibrils; this $\vec{\Rightarrow}$ contributes to the firm coherence between the epidermis and the dermis, since the elastic fibrils are rigid and will not stretch.

In the syndrome described above it would seem probable that the peau d'orange or mottled appearance of the skin results from the rapid increase in the के fat and collagen deposited under the epidermis; this $\vec{\circ}$ would stretch the epidermis except in those parts held in position by the so-called elastic fibrils.

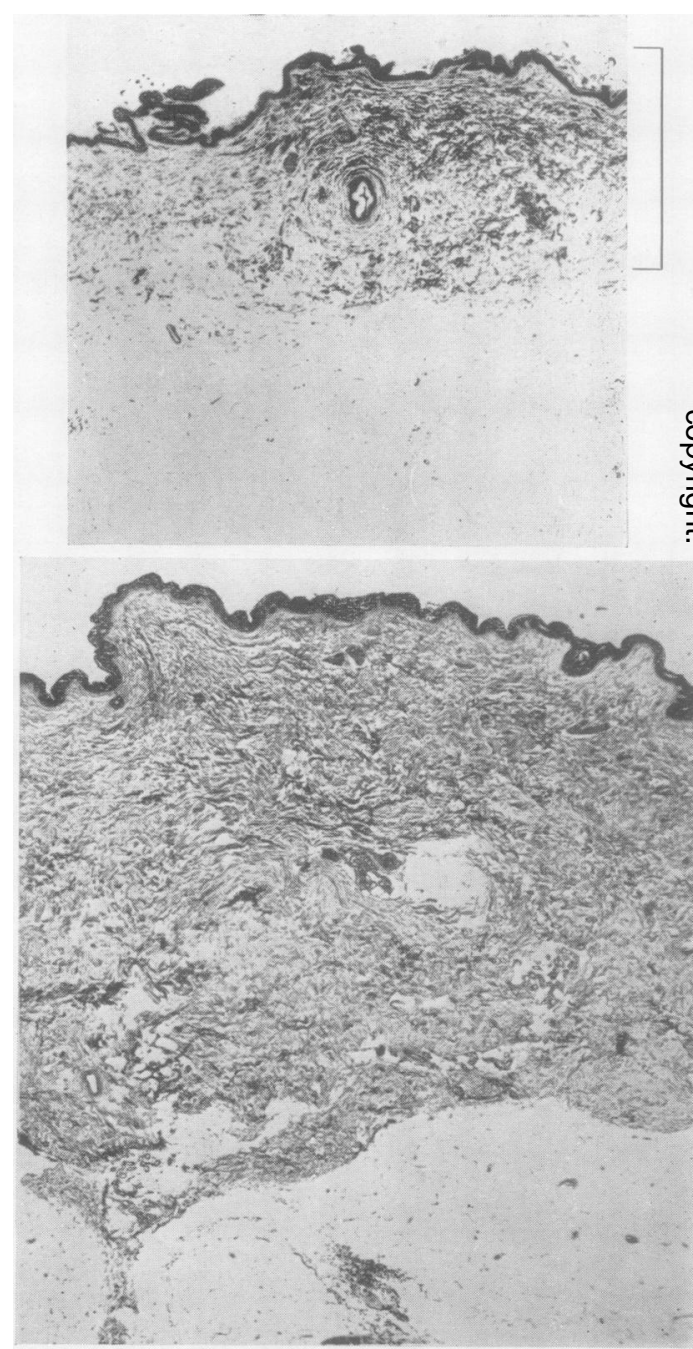

Fig. 4.-Skin from normal thigh (above), compared with skin from affected area (below). 
The pain and tenderness of the tense tissues may well be due to pressure on the small nerve endings with which the dermis is freely supplied. The patient feels the burning pain characteristic to the skin and there would also be paraesthesiae and tenderness on palpation. Aggravation of the symptoms by warmth would be produced by the vasodilatation of the numerous small blood vessels in the dermis, adding to the tension in the tissues.

Although increased depth of the collagen layer of the dermis would seem to be a major factor in producing the signs and symptoms in this syndrome, there is one other major factor, rapid increase in adipose tissue, and possibly a third, water retention.

Without exception, all the patients in my series gave a history of a rapid increase in weight. This seemed to have the purely mechanical effect of increasing the tension under the epidermis. No

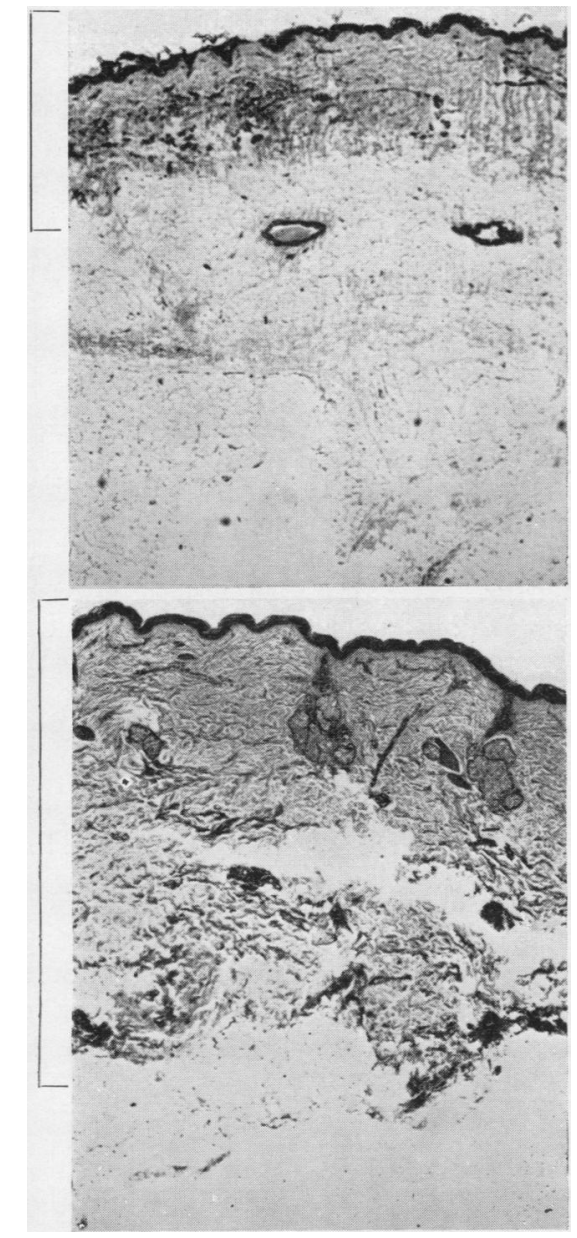

Fig. 5.-Skin from normal arm (above), compared with skin from painful shoulder (below). pathological change was detected in the fatty tissue, and obesity in itself is not a source of pain. It seems possible, however, that the adipose tissue could play a part in water retention, and abnormal water retention would be an added source of tension in the affected tissues. An experiment carried out by Copeman and Pugh (1945) gives some support to the theory of water retention; they selected 22 patients believed by them to be suffering pain due to increased fluid tension. By well-planned measures they obtained obligatory diuresis, designed to reduce the volume of the body fluid by extra-cellular, intracellular, and general dehydration; thirteen of the 22 patients were freed from pain for varying periods.

\section{Prognosis}

Since patients suffering from this syndrome with symptoms of sufficient severity to make them seek help at a clinic for rheumatic diseases are few in number, any statement as to prognosis must be drawn from personal experience only. The impression is that this is a self-limiting condition and that ultimately the symptoms disappear. The speed with which this takes place varies very much and is undoubtedly influenced by treatment. It seems reasonable to suppose that the epidermis will, in time, adjust itself to the added tension in the dermis, and that this will happen more quickly if the patient loses weight. In a follow-up of fifty patients over a period of 3 years, the important point emerged that those who lost an appreciable amount of weight were relieved of their symptoms, whereas those who remained stationary or gained in weight still have their complaints. Whether the collagen content of the dermis returns to normal there is so far insufficient evidence; it is not easy to gain consent to a biopsy of skin once a patient feels she has recovered.

\section{Incidence}

Enough cases have not yet been collected to warrant a statistical survey, but calculations based on the number of proved cases seen during one year at two clinics for rheumatic diseases suggest that approximately 0.5 per cent. of all female patients are suffering from some form of this syndrome.

\section{Treatment}

Although this would appear to be a self-limiting condition, it may give rise to symptoms for a period of years. My follow-up of a series of fifty cases covers 4 years and shows that after 3 years patients can still have symptoms, although some become symptom-free in a few months. Because no one is willing to endure discomforts for an indefinite length of time, some form of treatment is essential; promise of eventual relief is not enough. The 
main purpose of treatment is to reduce the tension under the epidermis, thereby relieving the pressure on the small nerve endings.

General Measures.-The first requirement is gradual but steady reduction in weight; the loss must go on until the patient is back to or a little below their usual weight before the rapid increase. This can be achieved, if the patient co-operates, with a 1,000-calorie diet or any good reducing diet. Since water retention may be a factor in this syndrome, a low-sodium intake is also required. If there are no contraindications small doses of thyroid can be prescribed.

These patients are entitled to analgesics, particularly to give them freedom from pain at night.

Physical Measures.-One of the most useful measures is planned general exercises, and the patient should be taught a simple scheme to carry out daily. Any form of heat or hydrotherapy, because it produces vasodilatation, is a painful form of treatment. Local measures such as massage to loosen up the tissues have a limited value and can be used in cases where small areas are involved.

Special Measures.-Phenylbutazone, so long as it does not induce water retention, seems to give a fair measure of relief and can be prescribed in suitable cases. Eight patients were materially relieved while taking $0.2 \mathrm{~g}$. twice daily, but three had some aggravation of their symptoms and there was some indication of water retention.

Cortisone was given to a small series of patients in doses of $75 \mathrm{mg}$. daily. The numbers were insufficient to draw definite conclusions, but where there was no evidence of water retention there was definite relief from symptoms. This did not, however, seem a treatment to recommend in view of the problems associated with its prolonged use.

Hall (1936), trying the effect of two oestrogenic substances in a condition he termed indifferently menopausal arthritis or arthralgia, claimed substantial benefit in 90 per cent. His description of the clinical picture is very similar to the syndrome under discussion and many of his patients had no demonstrable lesions in the joints. Chaouat (1951) also found the administration of dienoestrol effective in relieving pains associated with the menopause.

\section{Discussion}

Since the majority of these patients are women at or near the menopause, it is more than suggestive that this condition is the result of some endocrine dysfunction or hormone imbalance (Copeman, 1949). At the menopause there is a cessation of ovarian activity and the blood and urine in about 80 per cent. of women contain excessive amounts of gonadotropic hormones, indicating hyperactivity of the pituitary gonadotropic apparatus; this activity can result in obesity. Water retention, if $a$. factor in this syndrome, might point to an alteration? in the functioning of the posterior pituitary gland $\vec{F}$ since re-absorption of water by the tubules is con=trolled by the hormone of its posterior lobe.

As for the morbid anatomy, no firm statement can be made (until a further series of biopsies have been carried out) as to the increase in the depth of the collagen in the dermis of these patients. The highes percentage of positive findings so far does, however $\vec{P}$ make this change unlikely to be a chance discovery That this increased density is found in other con $\bar{\sigma}$ ditions is evidenced by a report of a similar changen in Milroy's disease (Lever, 1949).

There appears to be a close link between this $\vec{\Delta}$ syndrome and deposits of painful tissue round or near joints; Kling (1937) called this conditiono "juxta-articular adiposis dolorosa", Copeman (1949) more simply described the lesions as "periarticula? fat-pads". Kling carried out skin biopsies on six patients exhibiting this condition and reported:

The epidermis appears to be normal. The dermis consists in some sections of loose collagen fibres and in others of denser collagen fibres. Increase in the tension of the tissues is evidenced by the fae $\overrightarrow{0}$ quently found induration.

From clinical observation and from five biopsec so far carried out, these dense tender deposits, foutids most commonly in the region of the knee joint, seem to show the same morbid anatomy changes as are़ी found in this syndrome (Fig. 6). The position of these deposits would give rise to pain on movemenf of the joints and if not recognized could be diagnosed as osteo-arthritis. Gram (1930), writing on what he describes as "dolorous subcutaneous infiltrations" says that "the mobility of the knees is seldom. impaired", and describes the tissues as "infiltratec" and hard; a stiff armour-like infiltration".

It would seem that the greatest benefit that we can confer on these patients is to accord them the dignityo of a diagnosis which entitles them to treatment ans a fair measure of sympathy and understanding ${ }_{0}$ Diagnosis should not be difficult, but it should never? be made in the absence of the characteristic skit changes, and whenever possible these should beconfirmed by skin biopsy. This clinical syndromes still lacks a title. It should not be known as pannitu culitis; possibly panniculosis might be a better term

\section{Summary}

A new conception of the morbid anatomy of the्ष clinical condition hitherto known as panniculitiss? is presented and correlated with the signs ando 


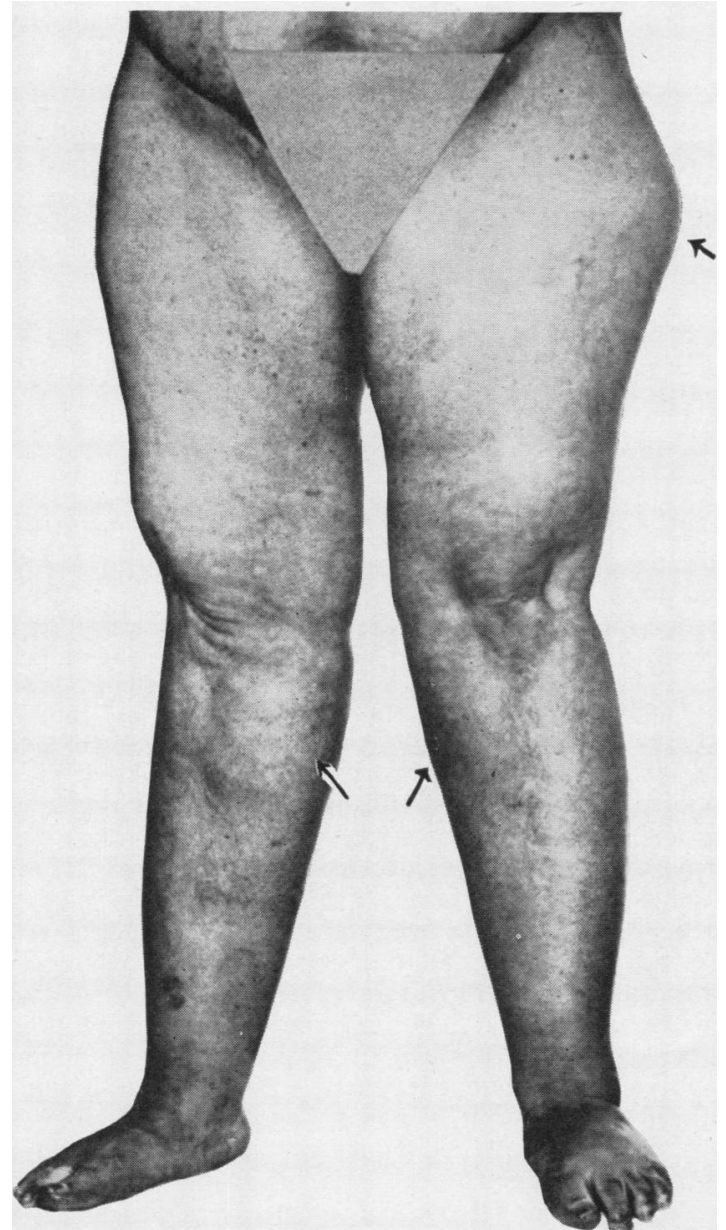

Fig. 6(a).-Enlarged area below patella on inner side of knees.

symptoms. Some unusual aspects of the syndrome are described, and suggestions made as to aetiology. Incidence, prognosis and treatment are discussed.

My thanks are due to Dr. Joan Haram, pathologist at the Elizabeth Garrett Anderson Hospital, whose original observations led me to a further study of this syndrome; to Miss Sylvia Fitton Jackson, engaged on research into the formation and development of connective tissue, for invaluable criticism and suggestions; and to Prof. R. Hare for help and advice on the presentation of the text.

\section{REFERENCES}

Baker, D. M. (1951). Lancet, 2, 753.

Chaouat, Y. (1951). Clinique (Paris), 46, No. 436, p. 11.

Copeman, W. S. C. (1949). Brit. med. J., 2, 191 .

Gram, H. C. (1930). Acta med. scand., $73,139$.

Hall, F. C. (1936). In "Medical Papers dedicated to Henry Asbury Christian in Honor of his Sixtieth Birthday", ed. R. T. Monroe, p. 928. Waverley Press, Baltimore, Maryland.

Kling, D. H. (1937). Arch. Surg., 34, 599 .

Kling, D. H. (1949). " "Histopathology of the Skin," p. 16. Lippincott, Philadelphia.

Stockman, A. (1911). Brit. med. J., 1, 352.

Telling, W. H. M. (1936). Clin. J., 65, 93.
}

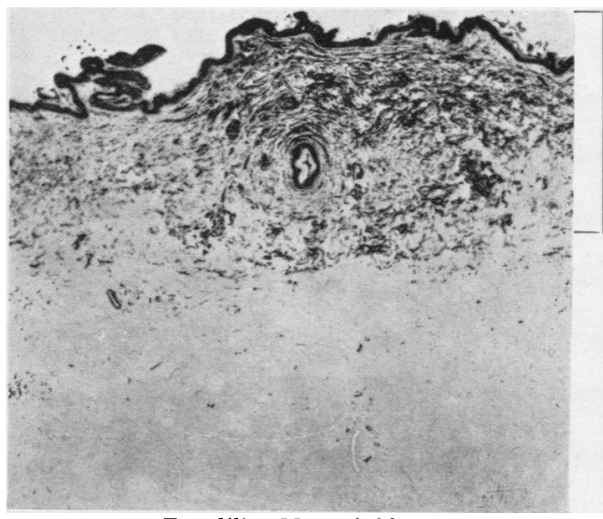

FIG. 6(b).-Normal skin.

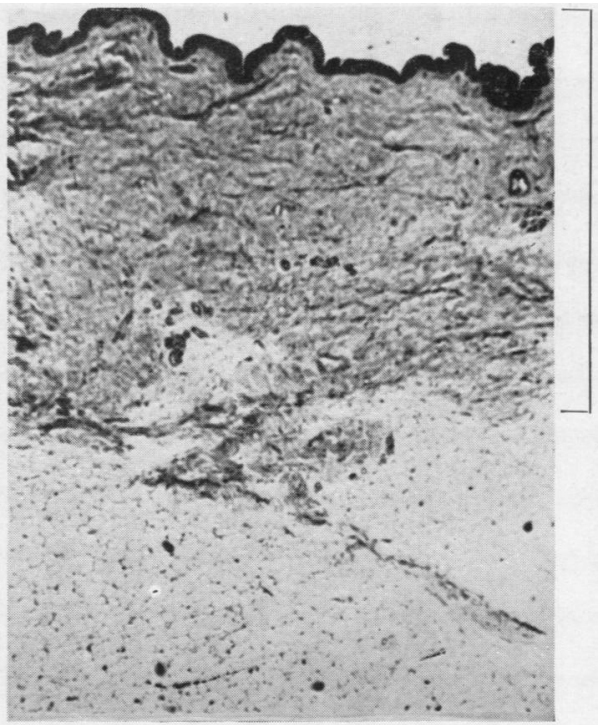

FIG. 6(c).-Skin from painful area.

Lésions des tissus dermiques et hypodermiques comme cause de la douleur rhumatismale

RÉSUMÉ

On présente une conception nouvelle de l'anatomie pathologique de l'affection connue en clinique sous le nom de panniculite et on la met en corrélation avec ses signes et symptômes. On décrit quelques aspects peu habituels de ce syndrome et on offre des idées concernant l'étiologie. On en discute brèvement la fréquence, le pronostic et le traitement.

\section{Lesiones del tejido dérmico e hipodérmico como causa de dolor reumático SUMARIO}

Se presenta un concepto nuevo de la anatomia patológica de la condición clínica conocida hasta ahora bajo el nombre de paniculitis, correlacionándole con los signos y síntomas. Se describen algunos aspectos poco comunes de este sindrome y se hacen sugestiones acerca de su etiología. Se discute brevemente la incidencia, el pronóstico, y el tratamiento. 